\title{
O DESIGN INSTRUCIONAL EM CURSO DE FORMAÇÃO CONTINUADA ATRAVÉS DO EAD SOBRE KITS EDUCATIVOS PARA PROFESSORES DA REDE PÚBLICA DE ENSINO DO ESTADO DA PARAÍBA
}

\author{
JOÃO PESSOA/PB JUNHO/2018
}

\author{
Dennisy Silva de Figueiredo - SEE/GOVPB - dennisysf@gmail.com \\ Hercilio de Medeiros Sousa - UFPB/UEAD - contato@herciliomedeiros.com.br \\ Estevão Domingos Soares de Oliveira - UFPB/UEAD - estevaodso@gmail.com \\ Euler Cássio Tavares de Macedo - UFPB/CEAR - euler@cear.ufpb.br
}

Tipo: Relato de Experiência Inovadora (EI)

Categoria: Métodos e Tecnologias

Setor Educacional: EDUCAÇÃo MÉDIA E TECNOLÓGICA, EDUCAÇÃo CONTINUADA EM
GERAL

RESUMO

O uso de Tecnologias na Educação constitui a oportunidade de explorar diversas formas para o desenvolvimento do processo de ensino-aprendizagem. As Tecnologias da Informação e Comunicação (TICs) são suportes para o processo e podem ser encontradas e utilizadas de diversas maneiras. $O$ Design educacional (DE) é um campo teórico que se divide em três aspectos: teoria, processo e produto. O seu principal objetivo é produzir, estratégicas, métodos e itens que facilitem a realização de metodologias educacionais, unindo o seu conceito a várias etapas de realização de soluções educacionais, que são criados para atender a uma necessidade de aprendizagem. No Ensino a Distância (EaD) o uso de TICs é frequente para atender as demandas dos alunos, além dos suportes utilizados. O EaD é uma forma de aprendizagem que necessita de organização e planejamento, além de produtos adequados pois com o seu caráter de distância entre alunos e professores/tutores, os método de ensino precisa ser eficaz e aproveitar as possibilidades existentes. Visando isso, buscou-se no Design educacional (DE) a resposta para o planejamento de uma solução educacional no EaD e a produção de produtos educacionais. Nessa busca, a oportunidade para realização de uma solução educacional surge através do Projeto de Pesquisa e Desenvolvimento (P\&D) entre a Universidade Federal da Paraíba e Governo do Estado da Paraíba que necessitam da capacitação de professores do ensino básico na utilização de kits didáticos. Para atingir o objetivo foi realizado o desenvolvimento de um curso de capacitação EaD para professores desenvolvido sob as estratégias, métodos e produtos do DE. A partir de fundamentos teóricos, o curso é construído em cinco etapas: análise, design, desenvolvimento, implementação e avaliação.

Palavras-chave: Educação Tecnológica. Design Instrucional. Design Educacional. Moodle. Capacitação 


\section{INTRODUÇÃO}

Há um grande crescimento das ofertas de Educação a Distância (EaD), como modalidade de educação que é presente no mundo e a muitas décadas pode ser encontrada no Brasil, com o seu início no século XIX. O EaD é a união entre Tecnologia e Educação, sua existência tem a intenção de suprir a necessidade de formação de um número elevado de pessoas, que hoje tem mais acesso à Educação, tornando-a democrática. Esse ensino apresenta um público identificável, geralmente são pessoas que trabalham, não têm tempo disponível para frequentar uma instituição de ensino regular mas desejam aprender e mudar sua realidade através da Educação. (MOORE, 2008) O Design Educacional (DE) ou Design instrucional (DI) é um campo teórico que realiza os processos de planejamento e implementação de ações educacionais, utilizando recursos didáticos. O DE passa por diversas fases na produção de uma solução educativa, se relaciona ao processo de concepção e desenvolvimento e com o produto gerado no processo para encontrar a solução. Devido ao seu caráter de distância física entre alunos e professores/instrutores o Design educacional é essencial para que a metodologia do EaD seja satisfatória e alcance o objetivo de formar os alunos em suas áreas de aprendizagem. Contudo, apesar do crescimento do EaD no mercado educacional, percebemos que ainda há faltas nos projetos educacionais no modelo a distância "O material didático para EaD [...] apresenta inadequações que variam "entre a superficialidade no tratamento da matéria à redução drástica de um típico livro-texto universitário para uma pequena apostila" (LITTO, 2009 in SILVA e SPANHOL, 2017).

Identificamos a necessidade de utilização do Design educacional para atender aos aspectos de ensino-aprendizagem para o $\mathrm{EaD}$, sua utilização e reconhecimento como elemento indispensável no desenvolvimento de soluções adequadas como processo prático de realização e geração de produtos. Relacionando a ausência de conteúdo adequado para o $\mathrm{EaD}$ de cursos que estejam preparados para realizar o processo de ensino-aprendizagem a distância e a identificação da solução pelo DE como processo, teoria e produto. Desde o lançamento do Plano de Desenvolvimento da Educação (PDE), hoje chamado Plano de Desenvolvimento da Escola (PDE - Escola), algumas iniciativas quanto ao investimento em ensino de qualidade e a utilização de tecnologias educacionais são realizadas pelo Governo Federal em parceria com os municípios, Estados ou com o Distrito Federal. Podemos citar o Guia de Tecnologias Educacionais, que oportuniza a aquisição de materiais e tecnologias para uso nas escolas públicas brasileiras. Entre os agrupamentos de tecnologias do Guia, encontramos a formação de profissionais da Educação, que pode ser realizada por EaD, segundo a legislação vigente. (EDUCAÇÃO, 2017). Visto isto, encontramos a oportunidade de explorar o 
Design educacional como processo através da construção de um curso de formação continuada para professores, a oportunidade surgiu a partir de um projeto de pesquisa e desenvolvimento (P\&D) realizado pelo Grupo de Pesquisa em Inteligência Artificial (GICA) e o Governo do Estado da Paraíba para a criação de tecnologias educacionais, entre elas, o treinamento de professores para a utilização de kits educativos. Devido ao número alto de escolas e professores, é necessário encontrar uma solução para o treinamento dos professores quanto a utilização dos laboratórios. A proposta sugerida é a criação de um curso de formação continuada, disponibilizado no formato EaD para esses profissionais da Educação atendendo a necessidade do projeto de P\&D dos kits.

\section{EDUCAÇÃO A DISTÂNCIA}

A Educação reúne os processos de ensino e aprendizagem e ao longo de sua história, passou por diversas transformações em suas metodologias e nas diversas formas de propagação e aquisição do conhecimento, acompanhando as mudanças das sociedades pelo mundo, desde a disseminação realizada de forma oral, realizada de pai para filho, com vivências diárias, até a utilização da tecnologia para o ensino à distância. (BRITO, 2008). No ano de 1996 foi implementada a primeira legislação específica para educação a distância no ensino superior no Brasil. A Lei de Diretrizes e Bases na Educação Nacional (LDB) de n॰9.394, que divide a educação escolar em educação básica e educação superior. Giolo (2008) discorre sobre o processo que estende-se após a LDB:

\footnotetext{
Inicialmente conduzido pelas instituições públicas, esse processo teve, em seguida, a partir de 2002, a participação agressiva do setor privado que, em pouco tempo, Ihe conferiu um perfil completamente diferente daquele imaginado pela legislação e, mesmo, daquele praticado pelas instituições públicas: de uma atividade complementar e subsidiária à educação presencial, tornou-se um objeto importante na disputa do mercado educacional.
}

A LDB discorre sobre o ensino superior, no art. 62 em relação a formação de docentes, observamos as considerações sobre a relação com o ensino a distância: " $§ 2^{\circ}$ A formação continuada e a capacitação dos profissionais de magistério poderão utilizar recursos e tecnologias de educação a distância. (Incluído pela Lei no 12.056, de 2009)." (BRASIL, 1996). Visto que a educação a distância é um instrumento de democratizante do ensino, onde os indivíduos podem ser instruídos em incontáveis campos de estudo, proporcionando aos alunos formações completas e de qualidade de acordo com a disponibilidade do aluno. A união entre a tecnologia e a educação, propõe diversas possibilidades, incluindo a formação continuada de professores, que são profissionais responsáveis pela formação de diversas camadas da sociedade.

Segundo o decreto no 6.094 de 25 de abril de 2007, o Governo Federal atua por meio de um Plano de Ações Articuladas (PAR), elaborado com cada município, Estado ou com o 
Distrito Federal. Entre as diversas ações criadas, encontra-se o Guia de Tecnologias Educacionais, segundo o site do Governo Brasileiro, Educação (2017): "oferecer aos gestores educacionais uma ferramenta a mais que os auxilie na aquisição de materiais e tecnologias para uso nas escolas públicas brasileiras." É dividido em cinco blocos de tecnologias: Gestão da Educação, EnsinoAprendizagem, Formação de Profissionais da Educação, Educação Inclusiva e Portais Educacionais.

\section{DESIGN EDUCACIONAL}

A tecnologia é mediadora do processo de ensino-aprendizagem onde alunos e professores se encontram em locais físicos diferentes, com modalidades on-line e no ensino presencial. A Educação a Distância é uma interação educação-tecnologia que apresenta diferentes modalidades, seja completamente on-line e no ensino semipresencial. A proposta de EaD necessita de um planejamento como afirmado por Moore; Kearley (2008, p.22) na definição do termo Educação a distância: Educação a distância é o aprendizado planejado que ocorre normalmente em um lugar diferente do local do ensino, exigindo técnicas especiais de criação do curso e de instrução, comunicação por meio de várias tecnologias e disposições organizacionais e administrativas especiais.

O Design educacional é um processo, ou uma série de etapas sugeridas, que os professores podem usar para planejar, implementar e avaliar suas instruções. Da mesma forma, ele pode ajudar-nos a utilizar o que está disponível para o alcance dos resultados de aprendizagem desejados. Originalmente desenvolvido como uma ferramenta para a concepção, implementação e avaliação corporativa, o Design educacional evoluiu como processo ao longo de vários anos e tem sido utilizado com muito sucesso nos anos mais recentes, em diferentes áreas de atuação educacional, com esforços significativos para encontrar os significados e as contribuições de sua aplicação também para setores de EAD em todos os níveis e modalidades de educação, incluindo as escolas públicas. Nota-se que a proposta de criação do curso de formação continuada para professores do ensino básico estadual seguindo o Design educacional contribui para o entendimento da construção de um curso na modalidade a distância com o objetivo de capacitar melhor os professores, relevante aos alunos da rede estadual de ensino que passarão por uma formação diferenciada através do uso de tecnologias educacionais. O DE apresenta como principal vantagem a clareza de que todo o processo de educação é realizado com foco nas necessidades do público-alvo, com o intuito de aprimorar competências, habilidades e desempenhos.

Seguimos como metodologia para a realização do curso em EaD, o processo do DE de acordo com Filatro (2015, p. 152) que divide o processo do Design educacional em cinco 
fases:

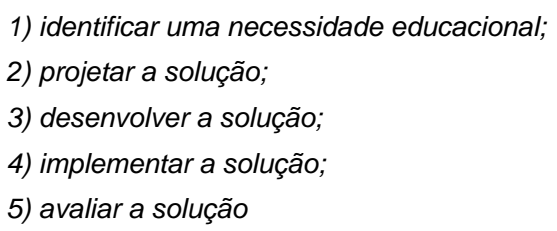

Quadro 1- Fases do projeto de Design educacional

\begin{tabular}{|l|l|}
\hline Fases do projeto & Atividade \\
\hline Análise & $\begin{array}{l}\text { Análise contextual: realizar um diagnóstico de necessidades de } \\
\text { aprendizagem }\end{array}$ \\
\hline Design & $\begin{array}{l}\text { Planejamento educacional: circunstanciar elementos pedagógicos, } \\
\text { tecnológicos, comunicacionais, informação e de gestão }\end{array}$ \\
\hline Desenvolvimento & $\begin{array}{l}\text { Autoria, Roteirização, Produção de Mídias: criação de produtos } \\
\text { educacionais de acordo com o planejamento }\end{array}$ \\
\hline Implementação & Aplicação em ambiente adequado dos produtos gerados \\
\hline Avaliação & Avaliação da qualidade da solução implementada \\
\hline
\end{tabular}

\section{O DESENVOLVIMENTO}

\section{Análise}

Segundo a Secretaria de Educação do estado da Paraíba6 são 204 dias letivos escolares, em que os profissionais da educação devem realizar o planejamento e executá-lo em sala de aula. De acordo com as Diretrizes Operacionais de 2017, as salas de aula da rede estadual de ensino devem conter no mínimo 20 alunos e no máximo 50 por turma. Entre os 223 municípios formantes do Estado, divididos em 14 regionais de gerência educacional, de acordo com o Censo (2015) são 8.159 docentes no ensino médio, distribuídos em 384 de ensino médio.

Anualmente é promovido pelo governo a premiação Escola de Valor e Mestres da Educação, os critérios de avaliação, além da inscrição no caso do primeiro prêmio: Projeto de Intervenção Pedagógica (PIP); relatório de execução do PIP; documentos comprobatórios; no segundo prêmio: Projeto do professor; relatório de execução do projeto; documentos comprobatórios. O prêmio tem a intenção de valorizar os professores que se destaquem por suas competências e práticas pedagógicas inovadoras, reconhecer e dar visibilidade ao profissional de Educação, igualmente as escolas que reconhecem seus gestores com o reconhecimento.

\section{Design}

Nesta fase, devido ao caráter de planejamento, conseguimos visualizar de maneira mais efetivo as alternativas que temos, os prováveis conflitos, indica-se a ordem de ações e prioridades além de programar o quanto precisamos nos dedicar e em quanto tempo 
alçaremos nosso objetivo, que é a aprendizagem, sempre avaliando os processos e decisões do processo educacional. (FILATRO, 2015). A matriz de planejamento foi criada com a proposta de conteúdos educacionais, que iremos justificar adiante.

Hipertexto através de e-book que é utilizado como guia de apoio ao docente, com o intuito de promover um suporte com conteúdo relevante para a prática em sala de aula, integrando os vários elementos que compõem o curso de formação continuada. A leitura não linear permite o acesso a outros textos de forma instantânea, através dos links propostos que pode ser explorado de forma livre pelos docentes, que são instigados a criarem sua própria trilha de aprendizagem, sem regras;

Imagem é um elemento que chama a atenção por ter em sua primeira visão a forma clara de sua mensagem principal, realizada com uma leitura breve. Segundo Filatro (2015, p. 273) "A explicação vem da abordagem cognitiva, segundo a qual a mente humana [...] processa imagens mentais, cria e manipula símbolos, e visualiza relações entre eles.". Utilizamos organizadores gráficos, imagens ilustrativas e ilustrações multiquadros;

Multimídia, segundo Mayer in Filatro (2015, p. 285) "utilização tanto de palavras ([...] texto falado ou impresso) quanto de figuras ([...]ilustrações, gráficos, diagramas, mapas, fotos, animações e vídeos).". Utilizamos a apresentação interativa com textos e animações;

Objetos de aprendizagem (OA) utilizamos simulações que são realizadas no kit físico, vídeos educativos, debates em fórum e jogo educativo.

\section{Autoria}

Utilizamos o conteúdo criado de forma adaptada, o conteúdo foi criado por integrantes do projeto educacional durante o desenvolvimento dos kits didáticos. O texto-base criado foi adaptado em algumas circunstâncias atendendo a formas de comunicação diferenciadas de acordo com a mídia escolhida, mudando o fluxo de informações conciliando com as estratégias de aprendizagem.

\section{Roteirização}

Para Filatro (2015, p. 230) a roteirização é uma etapa importantíssima, devido ao envolvimento de diferentes áreas: "[...] o objetivo por trás dos conteúdos é claramente educacional; também requer um olhar comunicacional porque prepara os conteúdos para serem comunicados em uma ou mais mídias, com suas linguagens específicas." Para nossa proposta, desenvolvemos storyboards (SB) de apresentação, que segundo Filatro (2015, p. 356) apresentam: "estética detalhada, colorida e próxima do resultado final para seduzir os interessados; poucas informações técnicas que são irrelevantes neste momento" para detalhar as unidades do curso e a proposição de atividades. 


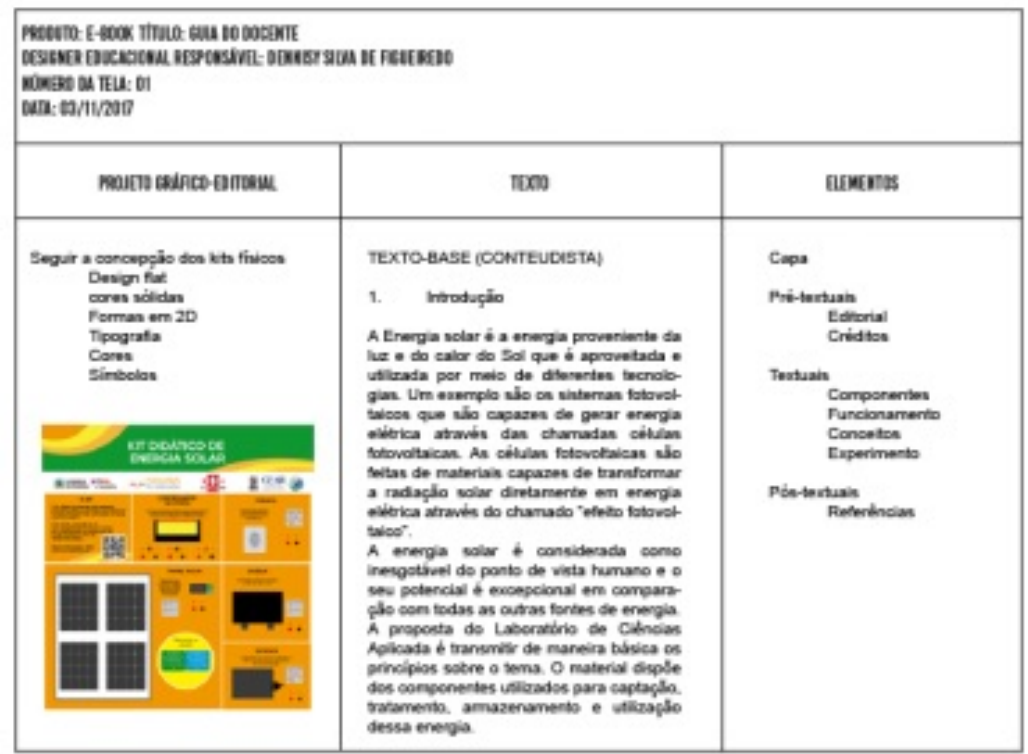

\section{Produção de Mídias}

O primeiro material desenvolvido a partir do storyboard criado, foi o Guia do Docente, realizado no software Indesign, com a utilização do texto-base e a formatação seguindo as orientações do design já utilizado. A apresentação Multimídia, que reúne elementos os elementos visuais imagens, texto, gráficos e animações foi realizado no software Interlude.
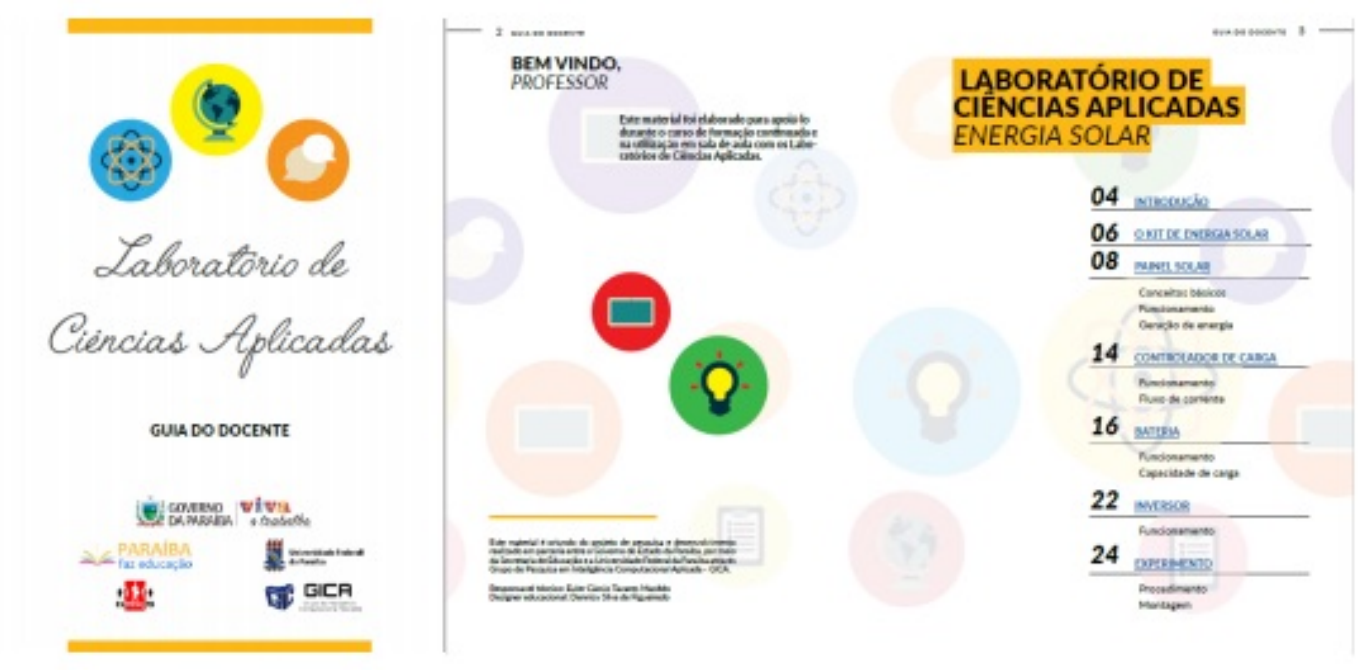

\section{IMPLEMENTAÇÃO}

Realizamos a implementação do curso na plataforma Moodle Cloud, sistema disponibilizado on-line de com pacotes de uso, que resumem em cinco tipos, diferenciados entre si pela quantidade de usuários por site, quantidade de armazenamento de dados, temas e plug-ins. Optamos pela utilização do pacote gratuito que apresenta algumas limitações mas atende a nossa necessidade de implementação para o projeto desenvolvido. O serviço oferecido apresenta uma estrutura já tradicional para curso em EaD, com a possibilidade de personalização de alguns elementos 
gráficos e a proposta de implementação de diversas atividades. Para a vivência do curso, durante o cadastro no site do Moodle Cloud, criamos o seguinte endereço para acesso ao curso: https://labcienciasaplicadas.moodlecloud.com. A partir deste endereço, o usuário terá acesso a tela inicial. Inicialmente, de acordo com o pacote escolhido, os usuários devem ser cadastrados pelo administrador do site para terem acesso ao curso, essa forma de acesso garante um maior controle sobre o público que terá acesso ao curso.

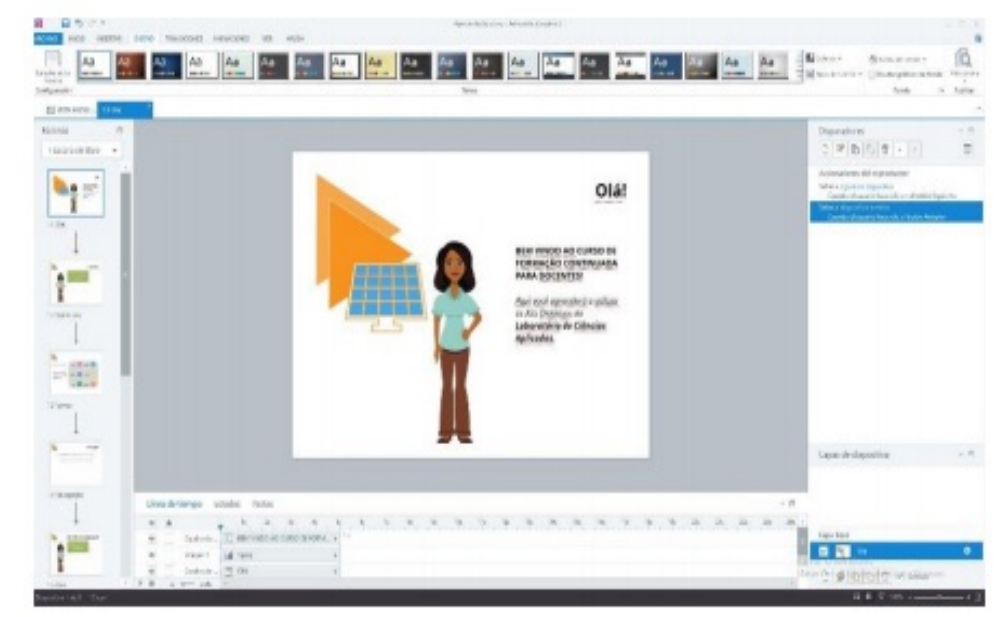

Após a realização do login, o usuário tem acesso a área de cursos, no momento disponibilizamos o curso desenvolvido para o trabalho, intitulado de Módulo I - Kit de Energia Solar, a partir dele, o usuário acessa a tela onde há toda a estrutura disponível do curso. O curso, que de acordo com a plataforma Moodle, pode ser formatado em tópicos, atividade única, social e semanal. Optamos pelo formato de tópicos, que foram divididos em seis: Apresentação, Unidade 1, Unidade 2, Unidade 3, Unidade 4 e Unidade 5. No tópico Apresentação, dividimos as atividades em:

- Glossário, com o objetivo de ser uma atividade colaborativa, construída pelos próprios participantes;

- SCORM15, desenvolvido no software Articulate, que realiza o processo de interação entre as informações passadas e os usuários com diversas atividades;

- Arquivo, disponibilizamos um arquivo no formato PDF para consulta sobre o significa dos símbolos utilizados e

- Fórum, onde os usuários do curso realização interações entre os participantes e poderão criar relações durante a capacitação. ?

\section{AVALIAÇÃO}

Em um estudo sobre modelos de avaliação para cursos a distância, há uma discussão sobre variados tipos de avaliação e de modelos construídos sobre critérios específicos, entre eles, destacamos o modelo de avaliação que Neder in Rodrigues (1998, p. 60) 
destaca alguns elementos de maior significação para a avaliação da dimensão didáticapedagógica, que considera os seguintes aspectos:

1.avaliação da aprendizagem, considerando que o que deve importar é o desenvolvimento da autonomia crítica do aluno, frente a situações concretas que se lhes apresentem;

2.avaliação do material didático - pelo aluno, pelo orientador acadêmico, pelo autor e pela equipe de ED;

3.avaliação da orientação acadêmica - pelos alunos, pelo coordenador do centro de apoio e pelo núcleo de ED; e, 4.avaliação da modalidade de ED - a soma dos itens anteriores mais aspectos administrativos e dos acordos interinstitucionais.

Baseado nos aspectos citados anteriormente desenvolvemos um questionário com o intuito de validação do curso por um grupo específico, como proposta de avaliação futura, visto que atualmente não contamos com tempo hábil para a realização da validação. A construção do questionário é abordada por questões relacionadas a cada um dos aspectos expostos.

\begin{tabular}{|c|c|c|}
\hline Número & Questão & Opções \\
\hline 01 & O acesso ao curso apresenta um grande nivel de dificuldade? & $\begin{array}{l}\text { Sim; Não; } \\
\text { Justifique. }\end{array}$ \\
\hline 02 & $\begin{array}{l}\text { Você identifica a necessidade de uma experiência prévia sobre } \\
\text { o Ambiente de aprendizagem? }\end{array}$ & Sim; Não; \\
\hline 03 & $\begin{array}{l}\text { O curso é destinado a um público de aproximada } 8.000 \\
\text { pessoas, sabendo desta informação, você considera o curso em } \\
\text { ensino a distância uma proposta adequada quanto a custos de } \\
\text { distribuição? }\end{array}$ & $\begin{array}{l}\text { Sim; Não; } \\
\text { Justifique. }\end{array}$ \\
\hline 04 & $\begin{array}{l}\text { Sobre o conteúdo do curso, a organização do curso está clara? } \\
\text { Quanto a sua divisão e sequência? }\end{array}$ & $\begin{array}{l}\text { Sim; Nào; } \\
\text { Justifique. }\end{array}$ \\
\hline 05 & $\begin{array}{l}\text { Considera o curso inovador quanto as tecnologias } \\
\text { empregadas? (Design educacional, EaD, Articulate) }\end{array}$ & $\begin{array}{l}\text { Sim; Não; } \\
\text { Justifique. }\end{array}$ \\
\hline 06 & $\begin{array}{l}\text { O tempo proposto para a capacitação é de duas horas para a } \\
\text { sua realização on-line, excluindo as atividades práticas } \\
\text { propostas, é um prazo adequado para o conteúdo? }\end{array}$ & $\begin{array}{l}\text { Sim; Não; } \\
\text { Justifique. }\end{array}$ \\
\hline 07 & $\begin{array}{l}\text { Os produtos desenvolvidos para o curso, como Guia do } \\
\text { Docente, Aulas interativas, Fóruns estão adequados ao } \\
\text { objetivo do curso? }\end{array}$ & $\begin{array}{l}\text { Sim; Não; } \\
\text { Justifique. }\end{array}$ \\
\hline
\end{tabular}

\section{CONSIDERAÇÕES FINAIS}

Executar a produção de um curso em EaD é um desafio, principalmente para aqueles que se tornam Designer Educacional em diversas etapas do projeto. São várias atividades diversificadas que são envolvidas no processo produtivo que da perspectiva de um Comunicador é enriquecedor e desafiador devido ao grau de importância do produto e da influência de suas decisões no processo de aprendizagem. A proposta de criar um curso em EaD para professores foi realizada seguindo o DE que nos mostra a importância de cada etapa e o quanto o ensino-aprendizagem é o elemento central dessa prática. Ampliamos a nossa compreensão do ensino a distância, suas estratégias e a contribuição do DE na construção de objetos educacionais. 
Descobrimos a importância do trabalho em equipe para o desenvolvimento de um projeto educacional. Utilizar a autora Andréa Filatro como principal fonte de referência, abriu o número de possibilidades existentes para a produção de conteúdos educacionais que se expandem a cada momento e aumentam o seu grau de importância diante da necessidade de formação que todos os indivíduos em sociedade necessitam, o material de sua autoria, segue a proposta de DE e a leitura e o entendimento é facilitado e com o objetivo claro de aprendizagem. Neste produto, conseguimos seguir uma das inúmeras formas de realização em DE, a cada etapa nos é apresentado variadas possibilidades de abordagem, de intenção o que aperfeiçoa nossas propostas e produtos, o desenho educacional se torna mais complexo para os produtores e completo para os receptores de conteúdo. $O$ trabalho em equipe é um elemento fundamental para que a dinâmica do envolvimento de tantas áreas que são contempladas da melhor maneira possível. $O$ potencial pedagógico, unido a Comunicação, Tecnologias, Ciências e Gestão nos apresenta resultados excelentes, que realizam o principal objetivo do $D E$, que é a aprendizagem.

\section{REFERÊNCIAS}

BRITO, Glaucia da Silva. Educação e novas tecnologias: um re-pensar / Gláucia da Silva Brito, Ivonélia da Purificação. 2. ed. rev, atua. e ampl. - Curitiba Ibpex, 2008. 139 p. Disponível em: . Acesso em: 29 de outubro de 2017, 20:30:30.

EDUCAÇÃO, Ministério da. Guia de Tecnologias. Disponível em: . Acesso em: 21 de maio de 2018, 21:41:30.

Plano de Desenvolvimento da Escola (PDE - Escola). Disponível em: . Acesso em: 21 de maio 2018, 19:21:00.

FILATRO, Andrea. Produção de conteúdos educacionais / Andrea Filatro, Sabrina Cairo. - São Paulo: Saraiva, 2015.

GIOLO, Jaimes. A educação a distância e a formação de professores. Educ. Soc., Campinas, vol. 29, n. 105, p. 1211-1234, set./dez. 2008. Disponível em: . Acesso em: 29 de outubro de 2017, 00:10:00.

MOORE, Michael G. Educação a distância: uma visão integrada / Michael G. Moore, Greg Kearsley; [tradução Roberto Galman]. -- São Paulo: Cengage Learning, 2008.

RODRIGUES, Rosângela. Modelo de avaliação para cursos no ensino a distância: estrutura, aplicação e avaliação. Florianópolis, 1998. Disponível em: . Acesso em: 04 de novembro de 2017, 20:01:00.

SILVA, Andreza; SPANHOL, Fernando. ARIADNE: solução para gestão no design educacional. Disponível em: < https://goo.gl/8629Fe>. Acesso em: 29 de outubro de 2017, 22:21:00. 